\title{
The view from space
}

\author{
Tony Delamothe deputy editor, BMJ
}

What would extraterrestrials make of life on earth if all they had to go on was this year's Christmas BMJ? Such an event is not so unlikely. A corrupted line of computer code could easily beam the issue's contents out to Alpha Centauri rather than on to readers' iPads.

Given that so many articles focus on times past, extraterrestrials' overwhelming impression might be that earthlings are happier looking backwards than forwards. The past may be another country, but that's apparently where they prefer to live.

Setting the scene is the first editorial, which hymns a prelapsarian past before NHS managers seized the whip hand from doctors (doi:10.1136/bmj.e8239). Less fraught nostalgia is on offer in articles on the short lived genre of gastroscopic painting (doi:10.1136/bmj.e8323), how successive editions of a popular textbook charted changing obstetric fashions over the years (doi:10.1136/bmj.e8270), and an extraordinary series of drawings made in operating theatres (doi:10.1136/bmj.e8529).

Some articles mine the past explicitly for its relevance to the present. The editorial on hospital acquired infection draws parallels between the behaviour of contemporary British doctors and the Viennese obstetricians who made life difficult for Ignaz Semmelweis in the 19th century (doi:10.1136/bmj.e8330).

Concerned extraterrestrials will be cheered that the problem of hospital infections is about to be solved, thanks to a combination of capes (doi:10.1136/bmj.e8286) and sniffer dogs (doi:10.1136/ bmj.e7396).

Roger Kneebone and Abigail Woods have set about capturing the disappearing world of open surgery because they believe that such a record could prove useful after its practitioners have died out (doi:10.1136/bmj.e8135). Richard Smith looks to the stunningly successful British campaign to abolish slavery (1787-1807) as a model for tackling today's seemingly intractable problems: the pandemic of non-communicable diseases, climate disruption, and global poverty (doi:10.1136/ bmj.e8301).
Continuing the theme of mining the past to inform the present, two articles and an editorial examine the survival of Olympic athletes in the years following their triumph (doi:10.1136/bmj. e8308, doi:10.1136/bmj.e7456, doi:10.1136/bmj.e8338). The main aim of this trio is to ascertain whether being superfit increases one's survival. Extraterrestrials could conclude that earth must be a great place to live if its inhabitants will consider doing anything so extreme to increase their time there.

Two papers look at the threats to healthy living. Simon Howard and colleagues compared meals cooked by television chefs with those of supermarkets' own brands (doi:10.1136/bmj.e7607). On average, TV chefs' meals had higher total fat, saturated fat, and sugar content than supermarket meals. No meal complied fully with WHO dietary recommendations. Jennifer Mindell and colleagues describe the insidious capture of the health promotion agenda in Britain by the private sector, aided and abetted by the current government (doi:10.1136/bmj.e8082). David Spiegelhalter despairs of the plethora of terms for quantifying the risks of lifestyle activities and suggests "microlives" as a more comprehensible alternative for those interested in living longer (doi:10.1136/bmj.e8223).

The journal ends with two articles of more than academic interest to alien readers. The first describes how, 50 years after earth sent a man into space, this opportunity is now available to anyone who can afford it (doi:10.1136/bmj.e8124). Given that many early customers will be old (in earth years), there's likely to be a hike in the number of inflight emergencies; perhaps low flying extraterrestrials will be able to help out. We hope potential Good Samaritans will want to do so, after reading about the solicitous, if uncomprehending, care meted out to one of their number, mistakenly abandoned in suburban America (doi:10.1136/bmj.e8127).

๑ BMJ Publishing Group Ltd 2012 